Martin Ahrens

Aktuelles Privatinsolvenzrecht 


\section{ZIP Praxisbuch 8}




\title{
Aktuelles Privatinsolvenzrecht
}

\author{
Reform und neue Entwicklungen
}

3. überarbeitete und ergänzte Auflage

von

Prof. Dr. Martin Ahrens, Göttingen

\section{RWW}

RWS Verlag Kommunikationsforum GmbH · Köln 
Die Deutsche Nationalbibliothek verzeichnet diese Publikation in der Deutschen Nationalbibliografie; detaillierte bibliografische Daten sind im Internet über http://dnb.d-nb.de abrufbar.

\section{(C) 2019 RWS Verlag Kommunikationsforum $\mathrm{GmbH}$}

Postfach 2701 25, 50508 Köln

E-Mail: info@rws-verlag.de, Internet: http://www.rws-verlag.de

Das vorliegende Werk ist in all seinen Teilen urheberrechtlich geschützt. Alle Rechte vorbehalten, insbesondere das Recht der Übersetzung, des Vortrags, der Reproduktion, der Vervielfältigung auf fotomechanischem oder anderen Wegen und der Speicherung in elektronischen Medien.

Satz und Datenverarbeitung: SEUME Publishing Services GmbH, Erfurt Druck und Verarbeitung: Hundt Druck GmbH, Köln 